J. Clin. Chem. Clin. Biochem.

Vol. 27, 1989, pp. $331-336$

(C) 1989 Walter de Gruyter \& Co.

Berlin · New York

\title{
Efficacy and Safety of a Polyester Leukocyte Removal Filter for Whole Blood and Red Cell Concentrate Filtration
}

\author{
By J. Lindena
}

Abteilung Klinische Biochemie, Medizinische Hochschule Hannover

\section{S. Papastavrou and J.-W. Seidel}

Abteilung Immunhämatologie und Transfusionsmedizin, Medizinische Hochschule Hannover, Hannover, F. R. G.

(Received September 28, 1988/January 11, 1989)

Summary: Patients receiving multiple whole blood transfusions often experience adverse clinical symptoms caused by leukocytes. In the present study, the efficacy and safety of a polyester filter for leukocytes (Sepacell R-500) was evaluated. Donor units of whole blood and red cell concentrate stored for varying lengths of time were filtered. Emphasis was placed on humoral parameters indicative of release and/or activation reactions of granulocytes (neutral proteinase elastase, lysozyme, aggregation, chemiluminescence) and erythrocytes (lactate dehydrogenase, plasma haemoglobin). Nonspecific adsorption effects were investigated by plasma protein determinations (albumin, $\alpha_{2}$-macroglobulin). A complete blood cell count as well as values of haemoglobin and haematocrit were determined. Sepacell R-500 proved to be a highly efficient filter to the leukocyte depletion of blood. Our results of erythrocyte and granulocyte related humoral parameters provided no significant evidence of filtration mediated activation or releasing reactions of clinical consequence.

\section{Introduction}

Repeated transfusions of blood are commonly associated with the occurence of non-haemolytic febrile reactions. These can be prevented or lessened by transfusing blood which has been freed from leukocytes. Various procedures are currently used to produce relatively leukocyte-poor blood. Filtration techniques are the most common $(1-5)$. In the past, investigations concerning the filtration of blood using various filter types have concentrated on the degree of depletion of distinct cell types (1). Information concerning the mediated activation and release reactions of the differing cell types following mechanical filtration procedures is not available. The cell most likely to be implicated in adverse reactions is the neutrophil granulocyte due to its significant pathogenic capability. These cells can discharge large amounts of toxic oxygen species and lysosomal neutral proteinases upon chemical or mechanical stimulation. Reactive oxygen species and neutral proteinase have been implicated in the pathogenesis of acute tissue injury, particularly in the lung (6). The activation of granulocyte oxidative metabolism and neutral proteinase release have been detected during extracorporeal circuit procedures such as haemodialysis and cardiopulmonary bypass $(7-12)$.

The present investigation thus explores levels of relevant humoral and cellular parameters following filtration using a polyester filter (Sepacell R-500) whose leukocyte-depletion efficacy has been previously documented $(13,14)$.

In this investigation, we have concentrated on the behaviour of those parameters indicative of the release and/or activation of specific cell types. All experiments were performed with whole blood and red cell concentrates stored over varying lengths of time. 


\section{Materials and Methods}

Whole blood and red cell concentrate

Whole blood in citrate-phosphate-dextrose (Fenwal Laboratories, Deerfield, IL, USA) and red cell concentrates derived from whole blood were used. At the time of investigation samples were 1,5 or 10 days old. Samples were stored at $4{ }^{\circ} \mathrm{C}$.

\section{Filter}

All experiments were performed using Sepacell R-500 leukocyte removal filters (Asahi Medical Co. Ltd., Tokyo, Japan; distributed by Diamed, Cologne, FRG). The Sepacell filter consists of polycarbonate densely packed with sheets of polyester fibers. The filters were used according to the manufacturer's instructions. Aliquots of whole blood were obtained pre- and postfiltration.

\section{Haematology}

Red cell, leukocyte, and platelet counts, haemoglobin and haematocrit were determined using a Coulter counter S-Plus IV (Coulter Electronics, Hialeah, Fla, USA).

\section{Plasma chemistry}

Plasma $(12000 \mathrm{~g}, 10 \mathrm{~min})$ was frozen and stored at $-70^{\circ} \mathrm{C}$. Standard procedures were applied for the determination of lactate dehydrogenase, plasma haemoglobin, granulocyte elastase as elastase- $\alpha_{1}$-proteinase inhibitor complex (complexed elastase) and lysozyme (15-17). Albumin and $\alpha_{2}$-macroglobulin were determined by nephelometric methods.

\section{Isolation of granulocytes}

Granulocytes from normal blood donors were isolated from the interface of a two-step discontinuous Percoll gradient (18).

\section{Granulocyte functional tests}

$-$

Granulocyte aggregation was measured using donor granulocytes $\left(1 \times 10^{7}\right.$ cells). Fifty microliters of unit plasma were brought to a final volume of $1 \mathrm{ml}$. Aggregation responses were quantitated from the increases in light transmittance (19).

Luminol-enhanced chemiluminescence of donor granulocytes $\left(0.5 \times 10^{5}\right.$ cells) was induced with zymosan, a particulate stimulus, and amplified with the addition of autologous unit plasma (CL 1). Controls (K1) without zymosan were also run (20). Chemiluminescence was measured with the Biolumat LB 9505 (Berthold, FRG) at $37^{\circ} \mathrm{C}$.

Two chemiluminescence parameters were calculated from the measurements:

(i) peak maximum counts/min (per $0.5 \times 10^{5}$ granulocytes) for the stimulation reaction (CL1) as well as for the control (K1), representing the oxygenation capacity and the native chemiluminescence, respectively.

(ii) peak time values (min) seen as time in minutes required to reach the peak maximum, representing the degree of receptor affinity and/or concentration.

\section{Statistics}

Statistical analyses were performed by Student's paired t-test. Significant differences between pre- and post-filtration values are given by: $2 \mathrm{p}<0.05^{*}, 2 \mathrm{p}<0.01^{* *}$ and $2 \mathrm{p}<0.001^{* * *}$.

\section{Results}

The results of filtration experiments using whole blood and red cell concentrate units stored from 1 to 10 days are given in table 1 and table 2 , respectively. Leukocytes and thrombocytes were removed to a significant degree from whole blood as well as from red cell concentrates. The number of erythrocytes, on the other hand, remained unchanged by the filtration process.

Certain humoral parameters are indicative of erythrocyte integrity during storage and before and after filtration. Plasma haemoglobin and lactate dehydrogenase levels increased with the duration of storage. Filtration-dependent increases were observed in plasma haemoglobin levels in red cell concentrate units from the first day of storage and in whole blood after 10 days of storage.

Levels of granulocyte secretory products in plasma (complexed elastase, lysozyme) increased with the duration of storage time and remained unaffected by filtration.

Levels of plasma proteins such as albumin and the protease inhibitor $\alpha_{2}$-macroglobulin were unaffected by either the duration of storage or filtration, as was also the case for haemoglobin and haematocrit. For 22 units of whole blood and 15 units of red cell concentrate the mean $( \pm S D)$ post-filtration weight was $90.2 \%( \pm 4.9 \%)$ and $85.6 \%( \pm 5.6 \%)$ of the prefiltration weight, respectively, and the mean ( \pm SD) filtration time was $5.4 \mathrm{~min}( \pm 1.5 \mathrm{~min})$ and $5.1 \mathrm{~min}$ $( \pm 2.6 \mathrm{~min})$, respectively. However, 10 of the 37 units required more than $20 \mathrm{~min}$ for filtration. These units were $\leq 5$ days old ( 2 units of whole blood, 8 units of red cell concentrate).

Neither aggregation- nor plasma-induced chëmiluminescence (K1) increased after filtration. Chemiluminescence induced by zymosan plus plasma (CL1) decreased after filtration.

\section{Discussion}

In the present investigation whole blood and red cell concentrates, stored for different times, were efficiently freed of leukocytes and platelets using a polyester leukocyte removal filter (Sepacell R-500). The absolute number of leukocytes remaining in a unit of filtered blood (ca. $\left.0.1 \times 10^{9} / 1\right)$ was far less than that $\left(0.5 \times 10^{9} /\right.$ unit $)$ usually required to produce nonhaemolytic febrile transfusion reactions in a sensitized patient (21). These results for leukocyte depletion are comparable with those previously reported for this type of filter $(12,13)$. 





蓄蓄蓄管

$+1+1+1+1+1$

꽁 융 ㅇํㅇ

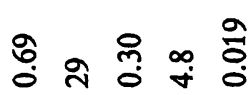

$+1+1+1+1+1$

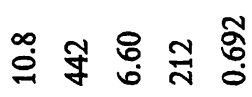

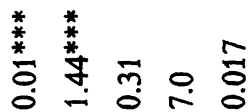

$+1+1+1+1+1$

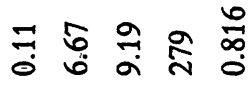

우 ₹

$+1+1+1+1+1$

חై

单

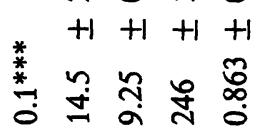

๙̃)

$+1+1+1+1+1$

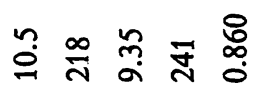

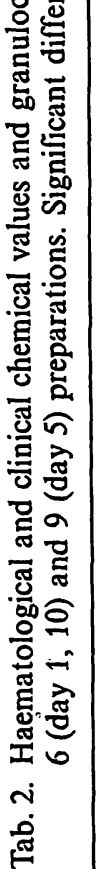

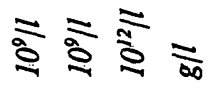

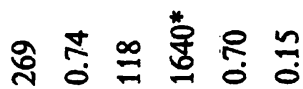

$+1+1+1+1+1+1$

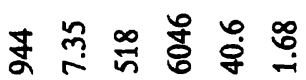

萠

$+1+1+1+1+1+1$

き

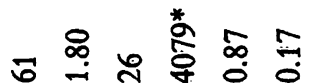

$+1+1+1+1+1+1$

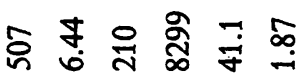

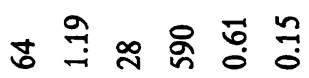

$+1+1+1+1+1+1$

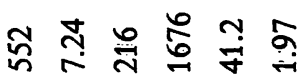

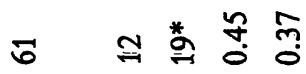

$+1+1+1+1$

ఫ 1 \&̊․

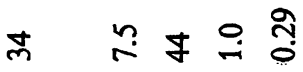

$+1+1+1+1$

ㄱ. 1 홍 홍
웅 $8 \stackrel{\text { 总 }}{+}$

$+1+1+1+1$

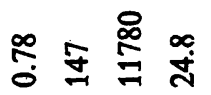

$\stackrel{\circ}{\circ}$ 으ำ 을

$+1+1+1+1$

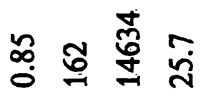

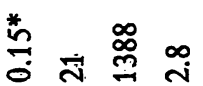

$+1+1+1+1$

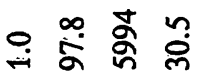

ஸึ่

$+1+1+1+1$

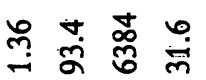

$\nabla \infty \underset{m}{\circ}$

$+1+1+1$

।

잉 $\stackrel{\infty}{\rightleftharpoons}$

$+1+1+1$

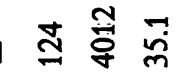

ะ ะ

§

$\times x$

हू

ते
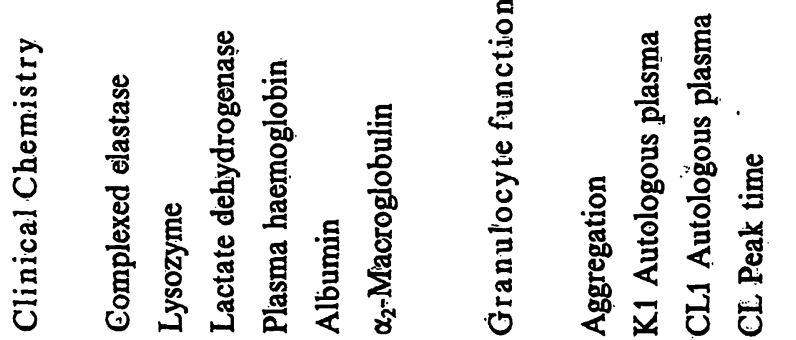

$\therefore$ 
The fact that platelets are removed to a large degree, however, makes this filter unsuitable for the preparation of leukocyte-poor platelet concentrates (22).

Similar values for haemoglobin, haematocrit and erythrocytes, before and after filtration, together with a lower post-filtration weight indicate that erythrocytes and plasma were proportionally removed by filtration. The loss, however, was small.

Apart from the question of the efficacy of this filter medium, the emphasis of this investigation has been placed on parameters indicative of the activation and integrity of granulocytes and erythrocytes and subsequent product release. Frequently observed adverse clinical reactions to other models of extracorporeal blood circuits, such as haemodialysis and cardiopulmonary bypass, have been ascribed to granulocyte activation with the concomitant generation of large amounts of toxic oxygen species (e.g. superoxide anion, hydrogen peroxide), discharge of primary and secondary granule contents (e.g. elastase, cathepsin) and complement activation $(7-12)$.

In the case of steadily increasing pre-filtration values, changes in the concentrations of the relative plasma parameters can be attributed to the duration of blood storage; whereas in the case of increased post-filtration values such changes can be attributed to the mechanical procedure of filtration itself.

Changes of the first type were observed for lactate dehydrogenase, plasma haemoglobin, complexed elastase and lysozyme. The increased concentrations are directly related to the duration of storage. These changes are within the range of previously reported changes observed as a result of long storage times $(23,24)$.

A filtration-related increase was observed for plasma haemoglobin. This increase was more drastic and the onset occured earlier in red cell concentrates. This is indicative of the increased fragility of erythrocytes due to prolonged storage. Plasma lactate dehydrogenase does not share this behaviour; it is probably inactivated (25). Due to the small plasma volume in red cell concentrates, relatively high plasma haemoglobin values should not be injurious to the recipient. Changes in the levels of granulocyte secretory products, such as elastase complexed with its natural inhibitor (complexed elastase) and lysozyme, did not occur. In contrast, increases in compexed elastase values of more than 10-times above normal have been observed during haemodialysis, depending on the type of dialysis membrane used $(8-11)$. These results based on humoral parameters do not indicate a filtration-mediated impairment of the integrity of granulocytes, whereas erythrocytes were slightly fragile after 5 days of storage. It has been shown that plasma, after travelling through various extracorporeal circuits, as commonly occurs in techniques such as filtration cytapheresis (26), haemodialysis (7) and cardiopulmonary bypass (12), generates distinct granulocyte-activating products. These complement-splitting products ( $\mathrm{C} 5 \mathrm{a}$ ) and immune complexes are potent stimuli, causing increases in aggregation and respiratory burst activity (chemiluminescence) of granulocyte target cells.

Granulocyte activation products in plasma, however, have not been observed using this type of filter. Increasing values for chemiluminescence and aggregation did not occur upon stimulation of donor granulocytes with plasma alone (K1) or in combination with a particulate stimulus such as zymosan (CL1). Decreased post-filtration chemiluminescence values following stimulation with zymosan plus autologous plasma (statistically significant for red cell concentrate), are the result of quenching by increased plasma haemoglobin values of added plasma (20).

Plasma protein adsorption by the polyester fibre software was not observed, as indicated by unchanged plasma protein values for albumin and $\alpha_{2}$-macroglobulin.

In about one fourth of the total number of filters evaluated, the filtration rate was slow, requiring more than $20 \mathrm{~min}$. As these units were $\geq 5$ days old they presumably contained enough microaggregates to block the pores of the filter. This fact and the above mentioned observation as to the higher fragility of erythrocytes $\geq 5$ days old support the suggestion of using blood less than 3 days old (27). Considering the present results, it is apparent that Sepacell R-500 is a highly efficient filter for leukocyte depletion of blood. No evidence of erythrocyte- and granulocyte-releasing and/or activation products were detected in postfiltration plasma for storage times of less than 5 days. Adverse clinical symptoms due to filtration using this filter are, therefore, highly improbable. 


\section{References}

1. Hughes, A. S. B. \& Brozovic, B. (1982) Br. J. Haematol. $50,381-386$.

2. Snyder, E. L. \& Bookbinder, M. (1983) Transfusion 23, 460-470.

3. Sirchia, G., Rebulla, P., Mascaretti, L., Greppi, N., Andreis, C., Rivolta, S. \& Parravicini, A. (1986) Vox Sang. 51, suppl. $1,2-8$.

4. Sirchia, G., Rebulla, P., Paravicini, A., Carnelli, V., Gianotti, G. A. \& Bertolini, F. (1987) Transfusion 27, 402405.

5. International forum (1986) Vox Sang. 50, 54-64.

6. Henson, P. M. \& Johnston, Jr. R. B. (1987) J. Clin. Invest. $79,669-674$.

7. Nguyen, A. T., Lethias, C., Zingraff, J., Herbelin, A., Naret, C. \& Descamps-Latscha, B. (1985) Kidney Int. 28, 158167.

8. Hörl, W. H., Schaefer, R. M. \& Heidland, A. (1985) Am. J. Nephrol. 5, 320-326.

9. Hörl, W. H., Steinhauer, H. B. \& Schollmeyer, P. (1985) Kidney Int. 28, 791-796.

10. Knudsen, F., Nielsen, A. H., Pedersen, J. O., Grunnet, N. \& Jersild, C. (1985) Int. J. Artif. Org. 8, 187-194.

11. Knudsen, F., Nielsen, A. H., Pedersen, J. O. \& Jersild, C. (1985) Scand. J. Clin. Lab. Invest. 45, 759-766.

12. van Oeveren, W., Kazatchkine, M. D., Descamps-Latscha, B., Maillet, F., Fischer, E., Carpentier, A. \& Wildevuur, C. R. H. (1985): J. Thorac. Cardiovasc. Surg. 89, 888-899.

13. Johnson, J., Mijovic, V. \& Brozovic, B. (1983) J. Clin. Pathol. 36, 1200-1201.

14. Johnson, E. J., Mijovic, V. \& Brozovic, B. (1984) J. Clin. Pathol. 37, 1415-1416.
15. The commission for enzyme diagnostics and standardisation. Recommendations of the German Society for Clinical Chemistry. Standardisation of methods for the estimation of enzyme activities in biological fluids. $Z$. Klin. Chem. Klin. Biochem. 10, $281=291$ (1972).

16. Neumann, S., Gunzer, G., Hennrich, N. \& Lang, H. (1984) J. Clin. Chem. Clin. Biochem. 22, 693-697.

17. Saint-Blancard, J., Chuzel, P., Mathieu, Y., Perrot, J. \& Jolles, P. (1970) Biochim. Biophys. Acta 220, 300-306.

18. Lindena, J., Wittenberg, H., Diederichs, F. \& Traütschold, I. (1986) J. Clin. Chem. Clin. Biochem. 24, 49-59.

19. Craddock, P. R., Hammerschmidt, D. E. \& White, J. G. (1977) J. Clin. Invest. 60, 261-264.

20. Lindena, J., Burkhardt, H. \& Dwenger, A. (1987) J. Clin. Chem. Clin. Biochem. 25, 765-778.

21. Perkins, M. A., Payne, R., Ferguson, J. \& Wood, M. (1966) Vox Sang. 11, 578-600.

22. Snyder, E. L., DePalma, L. \& Napychank, P. (1988) Vox Șang. $54,21-23$.

23. Shimizu, T., Ishikawa, Y., Tsurumi, H., Hibi, S., Takakura, R., Morishima, Y., Hasegawa, I. \& Goto, S. (1986) Vox Sang. 50, 203-207.

24. Jochum, M., Mempel, W., Fritz, H., Dwenger, A., Lindena, J., Schweitzer, G., Barthels, M. \& Trautschold, I. (1984) 18th Congress of the International Society of Blood Transfusion, Munich, p. 169.

25. Smit, M. J., Duursma, A. M., Bouma, J. M. W. \& Gruber, M. (1987) J. Biol. Chem. 262, 13020-13026.

26. Strauss, R. G., Spitzer, R. E., Stitzel, A. E., Urmson, J. R., Maguire, L. C., Koepke, J. A. \& Thompson, J. S. (1980) Transfusion 20, 32-38.

27. Sepacell R-500. Technical information, Asahi Medical Company Ltd., Tokyo, 1983.

Joachim Lindena, DVM

Abteilung Klinische Biochemie

Medizinische Hochschule Hannover

Konstanty-Gutschow-Straße 8

D-3000 Hannover 61 